\title{
NUTRITIONAL INTERVENTIONS FOR EARLY DEMENTIA
}

\author{
M. CESARI ${ }^{1,2}$, D. AZZOLINO ${ }^{1}$, B. AROSIO ${ }^{1,3}$, M. CANEVELLI $^{4,5}$ \\ 1. Department of Clinical Sciences and Community Health, University of Milan, Milan, Italy; 2. Geriatric Unit, IRCCS Istituti Clinici Scientifici Maugeri, Milan, Italy; 3. Geriatric Unit, \\ Fondazione IRCCS Ca' Granda Ospedale Maggiore Policlinico, Milan, Italy; 4. Department of Human Neuroscience, Sapienza University, Rome, Italy; 5. National Center for Disease \\ Prevention and Health Promotion, Italian National Institute of Health, Rome, Italy. Corresponding author: Matteo Cesari, MD, PhD. IRCCS Istituti Clinici Scientifici Maugeri; Via \\ Camaldoli 64 - 20138 Milan, Italy. Phone: +39 02 50725136. Email: macesari@gmail.com. Twitter: @ macesari
}

\begin{abstract}
Nutrition plays a critical role in the definition of the individual's wellbeing. Nutritional interventions have been repeatedly advocated as of potential interest for preventing or delaying the cognitive decline, also in the context of neurodegenerative conditions. The idea of targeting the initial phases of dementia, when the process is theoretically still amenable of correction, via lifestyle modifications (including healthy diet or supplementation of specific micro-/macro-nutrients) is extremely appealing. In this perspective paper, we describe the most recent evidence on the topic and discuss how the nutritional assessment should be nested within a comprehensive approach to the aging person with initial signs of dementia for promoting his/her optimal management.
\end{abstract}

Key words: Aging, cognition, supplementation, nutrition, geriatrics, neurology.

\section{Introduction}

Nutrition and dementia have been graphically presented as closely connected in a vicious cycle in recent guidelines published by the European Society for Clinical Nutrition and Metabolism (ESPEN) (1). Cognitive impairment may affect nutrition leading to a decrease of nutrients intake. The resulting weight loss and nutritional deficits may thus worsen the cognitive function of the individual, and concur at developing ancillary geriatric conditions (e.g., frailty, sarcopenia) (2-4). In other words, whereas adequate nutrition represents a critical component of healthy ageing in every individual, this becomes particularly true in the frailest persons as those living with dementia $(5,6)$. In fact, the neurological condition might implicitly expose the person to an increased vulnerability to stressors. Therefore, every reversible risk factor (such as decreased dietary intake, poor quality of foods, social isolation) should be carefully evaluated and corrected for preventing the onset of the disabling process (7).

A person with early dementia, usually characterized as having a Clinical Dementia Rating score of 1, is characterized by abnormalities at cognitive tests and has started experiencing difficulties in the conduction of his/her daily activities. The functional abnormalities can affect different domains (e.g., memory, orientation, judgment and problem solving, social activities, hobbies, personal care, affects) and in different ways. The result is that the phenotypic expression of a person with early dementia is usually extremely heterogeneous under biological, clinical, and social perspectives (8). Interestingly, some common issues found in persons with early dementia may play a relevant role in the alteration of nutritional patterns. For example, changes in olfactory and taste discrimination/ identification and food preferences, attention deficits, executive function deficits, impaired decision-making ability, and behavioral expressions (e.g., apathy, depression) may represent early manifestations in dementia altering the capacity of the individual to properly acquire the quantity and quality of needed nutrients $(1,9)$.

Nevertheless, despite the initial modifications of behaviors, persons with early dementia may not present major differences in nutritional status compared to healthy individuals. A recent study by Olde Rikkert and colleagues (10) compared a group of patients with mild Alzheimer's disease (AD) versus healthy controls for multiple micronutrients, anthropometric measures, and malnutrition assessment tools. Only few, relatively small, and far to be clinically relevant differences were found. A recent systematic review consistently showed that energy and protein intake in patients with $\mathrm{AD}$ is not substantially different from cognitively normal controls (11).

If the micro- and macronutrient intakes are not substantially different at the early stages of the dementia process, it might then be assumed that the general recommendations available for older persons directly apply to this group of patients. Indeed, the clinical consequences of an early stage disease may not yet produce evidence of major nutritional changes. Considering that older persons often presents multimorbidity $(12,13)$, it might be important to weight the burden of (early) dementia in the overarching clinical complexity of the individual. It becomes crucial to evaluate whether the cognitive dysfunction may simply be one of the many issues, without necessarily play a significant role in the definition of the patient's priorities.

In other words, whereas the dementia condition has not affected the nutritional status of the individual, the traditional recommendations available for promoting healthy aging in older persons can apply. Therefore, setting the optimal intake of dietary proteins to $1.0-1.2 \mathrm{~g} / \mathrm{kg}$ of body weight per day may become applicable independently of the presence of early dementia $(14,15)$. In case of concurrent acute illnesses, early dementia may play the role of an irrelevant comorbidity under the nutritional perspective, and the protein intake might simply 


\section{THE JOURNAL OF NUTRITION, HEALTH \& AGING}

be increased to $1.2-1.5 \mathrm{~g} / \mathrm{kg}$ of body weight per day as in persons without the neurodegenerative condition. Consistently, the evidence suggesting to 1) spread the dietary protein intake over different meals throughout the day (2), and 2) practice regular physical activity $(14,15)$ remains valid. In a person at the beginning of a clinical course characterized by increasing loss of autonomy, the maintenance of physical function (largely based on muscle health) becomes pivotal (16). For this reason, behaviors enhancing the protein synthesis and muscle preservation are actions of special relevance in the context of dementia (17). Another important aspect to consider in older persons with early dementia is the possible deficiency of vitamin $\mathrm{D}$, especially in those individuals who may have reduced their outside activities $(18,19)$. It is today demonstrated that the vitamin $\mathrm{D}$ acts as a pre-hormone; its receptor is not only located in bones but also in muscles (20). It is thus clear why the supplementation should be considered when low concentrations are reported. Furthermore, it is noteworthy how low concentrations of vitamin $\mathrm{D}$ have been associated with poor cognitive functioning and indicated as potentially involved in the incidence/worsening of dementia (21).

When discussing about nutritional needs in older persons and looking for possible solutions, the dramatically high prevalence of malnutrition should not be overlooked (22). Kaiser and colleagues (23) reported that more than one third of community-dwelling older persons are at risk of malnutrition or already malnourished. In this setting, there are likely many individuals with the first signs of dementia (24). The figures are even worse when observing other settings (e.g., hospital, rehabilitation) where persons with early dementia might be referred. Again, the early stage of the neurodegenerative disease might be a simple comorbidity in a subject with dysfunctions unrelated to the cognitive domain. The critical point is to detect the nutritional need, something that too frequently is neglected in the standard clinical care $(22,25)$.

In this context, we need to consider how malnutrition is the result a multidimensional mechanism (26). Social changes (e.g., poverty, living alone, eating alone), physiological modifications (e.g., sensory impairment, poor oral health, gastrointestinal disorders, lack of appetite), and psychological problems (e.g., depression, lower motivation) may heterogeneously combine, causing abnormalities in the eating process and consequent modification of food quality and quantity (27). It is also important to recall the so-called anorexia of aging phenomenon acting as underlying phenomenon predisposing to the onset of undernutrition $(28,29)$.

As above-mentioned, multimorbidity is a common feature of frail older persons $(30,31)$, and different clinical conditions might contribute at determining malnutrition in dementia through different mechanisms (32). For example, diseases can be responsible of poor protein and energy intake by increasing metabolism, generating anorexia, causing swallowing difficulties, and/or enhancing the age-related malabsorption of nutrients. In other words, every manifestation of malnutrition should be examined and evaluated on a case-by-case.

The complexity of nutrition in the context of dementia is exemplified in a recent document by Alzheimer's Disease International where the connection between poor oral health and cognitive impairment is shown (33). In particular, many nutrition-related factors (e.g., chewing capacity, infections, quantitative and qualitative adaptations of diet) are indicated as possible determinants of the cognitive decline. If the scenario becomes clearly difficult to disentangle because multiple systems (as well as social factors) are involved, many opportunities for preventing/reversing the vicious cycle of malnutrition arise. This means that, as also stated by the World Health Organization (WHO) in the World Report on Ageing and Health, "the management of malnutrition in older age needs to be multidimensional" (34).

Merging the need to be comprehensive and personalize interventions, the nutritional management of older persons with early dementia may thus be focused at those clinical features characteristic of the condition of interest (35). If the person with early dementia may not substantially different from a healthy individual under nutritional aspects, it is however true that some of his/her symptoms have to be considered in the design of a person-tailored preventive or therapeutic program on (the risk of) malnutrition. As such, attention deficits, executive function deficits, and impaired decision-making ability may be present and should be targeted by specific interventions when needed (1). For example, attention deficits may cause difficulties in shopping, preparing meals, and/or eating regularly. The solution might be represented by support with shopping and domestic help, including services as Meals-On-Wheels or the presence of a person at mealtimes. To avoid that the person with early dementia might forget to eat, supervision during meals, verbal prompting and encouragement have been recommended. Feeding assistance and adaptations to meals (e.g., energy-dense foods) may provide further support in the eating process.

Interestingly, the interventions for treating malnutrition (or, better, preventing it (36)) in older persons with dementia are often based on social support, further enhancing the multifaceted dimension of the nutrition process. In this context, the assessment of the older person with nutritional status should become integral part of the clinical evaluation. There is indeed the necessity to train physicians at recognizing the signs of malnutrition and act against it, eventually integrating ad hoc professionals in the process. Meijers and colleagues (37) showed a significant reduction of malnutrition across clinical settings after regular activities of auditing and monitoring were implemented. Surely, the busy activities and possible limitations of specific settings may not facilitate the evaluation that, after all, is not even adequately explained at the schools of medicine (traditionally focused at teaching about diseases and drugs rather than preliminarily providing the basic knowledge to promote healthy aging!).

Importantly, the need of acting in a comprehensive, 


\section{NUTRITIONAL INTERVENTIONS FOR EARLY DEMENTIA}

multidisciplinary, and coordinated way is the topic of the WHO document Integrated Care for Older PEople (ICOPE) [38], where a specific section is dedicated to malnutrition. It is here explained that nutritional supplements may surely play a role in recovering from severe deficiencies, although malnutrition requires a novel model of care for being tackled. The clinical condition typical of advanced age thus becomes a trigger for public health reorganization (39-41).

Beyond focusing on the effects of dementia on the individual's nutritional status, the interest of the scientific community is increasingly moving to the reciprocal perspective. That is, on the possibility of preventing or delaying the progression of dementia through nutritional interventions. In this regard, an international panel of experts recently convened that Souvenaid (a multinutrient product targeting synaptic dysfunction containing long-chain omega-3 fatty acids, uridine, choline, $\mathrm{B}$ vitamins, vitamin $\mathrm{C}$, vitamin $\mathrm{E}$, and selenium) should be considered as a therapeutic option in patients with prodromal $\mathrm{AD}$ or mild $\mathrm{AD}$ dementia (42). This advice was based on the results of randomized controlled trials of Souvenaid providing some evidence of efficacy in participants with early $\mathrm{AD}$, but not among those at the advanced stages of the disease (43-45). These trials, although mostly failing to demonstrate any significance on the adopted cognitive primary outcomes, showed that the product was well tolerated and documented significantly less worsening in the active treatment groups. Specifically, in the LipiDiDiet study, 311 subjects with prodromal $\mathrm{AD}$ were recruited and randomized to a 24-month treatment period with an optional 12-month doubleblind extension (43). There was no statistically significant difference between the Souvenaid and control group for a neuropsychological composite score (i.e., the trial primary endpoint) or on the conversion to dementia. Nevertheless, participants in the active group exhibited less cognitive and functional worsening and less reduction in hippocampal volumes. Despite these promising findings, several issues remain to be addressed and seem to somehow limit the validity and widespread adoption of expert recommendations. Indeed, the clinical meaningfulness of the observed cognitive changes still needs to be clarified. In other words, it is not clear if the measured cognitive and functional benefits were actually responsible for a real clinical improvement. In addition, costefficacy analyses should be performed in order to explore the sustainability of the intervention for our healthcare systems. Finally, the "real world" transferability of the available evidence, obtained in highly selected populations of individuals with positive biomarkers, is questionable.

In conclusion, persons with early dementia do not substantially differ in needs and priorities from communitydwelling older persons. Under this perspective, dementia is only one of the many possible clinical conditions of old age. It is thus important to contextualize each case. This can be done by approaching the individual's nutritional status in a comprehensive way in order to develop person-tailored interventions nested in a multidisciplinary and integrated model of care. The most perfectly designed pharmacological intervention will always fail if the fundamental basis of healthy living (i.e., social network, physical activity, healthy diet) are weak.

Conflicts of Interest: Dr. Cesari has received honoraria by Nestlé Health Sciences for presentations at scientific meetings and to serve as member of Expert Advisory Boards. No conflict of interest declared by the other authors.

Funding: Open access funding provided by Università degli Studi di Milano within the CRUI-CARE Agreement.

Open Access: This article is distributed under the terms of the Creative Commons Attribution 4.0 International License (http://creativecommons.org/licenses/by/4.0/), which permits use, duplication, adaptation, distribution and reproduction in any medium or format, as long as you give appropriate credit to the original author(s) and the source, provide a link to the Creative Commons license and indicate if changes were made.

\section{References}

1. Volkert D, Chourdakis M, Faxen-Irving G et al. ESPEN guidelines on nutrition in dementia. Clin Nutr 2015; 34: 1052-1073.

2. Calvani R, Miccheli A, Landi F et al. Current nutritional recommendations and novel dietary strategies to manage sarcopenia. J Frailty Aging 2013;2: 16.

3. Jung S, Hermann J, Bishop A. Impact of nutritional risk on self-care capacity: social support as a source of protection for community-dwelling older adults living in a rural area. J Frailty Aging 2013; 2: 145-149.

4. Landi F, Sieber C, Fielding RA, Rolland Y, Guralnik J, The ICFSR Task Force. Nutritional Intervention in Sarcopenia: Report from the International Conference on Frailty and Sarcopenia Research Task Force. J Frailty Aging 2018; 7: 247-252.

5. Burgener SC, Buettner L, Buckwalter KC et al. Evidence supporting nutritional interventions for persons in early stage Alzheimer's disease (AD). J Nutr Health Aging 2008; 12: 18-21.

6. Gillette Guyonnet S, Abellan Van Kan G, Andrieu S et al. IANA task force on nutrition and cognitive decline with aging. J Nutr Health Aging 2007; 11: 132-152.

7. The Orlando Frailty Conference Group. Raising awareness on the urgent need to implement frailty into clinical practice. J Frailty Aging 2013; 2: 121-124.

8. Kelaiditi E, Cesari M, Canevelli $\mathrm{M}$ et al. Cognitive frailty: rational and definition from an IANA-IAGG international consensus group. J Nutr Health Aging 2013; 17: 726-734.

9. Doorduijn AS, de van der Schueren MAE, van de Rest O et al. Olfactory and gustatory functioning and food preferences of patients with Alzheimer's disease and mild cognitive impairment compared to controls: the NUDAD project. J Neurol 2020; 267: $144-152$.

10. Olde Rikkert MGM, Verhey FR, Sijben JWC et al. Differences in Nutritional Status Between Very Mild Alzheimer's Disease Patients and Healthy Controls. J Alzheimers Dis 2014; 41: 261-271.

11. Doorduijn AS, van de Rest O, van der Flier WM, Visser M, de van der Schueren MAE. Energy and Protein Intake of Alzheimer's Disease Patients Compared to Cognitively Normal Controls: Systematic Review. Journal of the American Medical Directors Association 2019; 20: 14-21.

12. Wang R, Yan Z, Liang Y et al. Prevalence and Patterns of Chronic Disease Pairs and Multimorbidity among Older Chinese Adults Living in a Rural Area. PLoS One 2015; 10: $\mathrm{e} 0138521$

13. Abad-Díez J, Calderón-Larrañaga A, Poncel-Falcó A et al. Age and gender differences in the prevalence and patterns of multimorbidity in the older population. BMC Geriatr 2014; 14: 75.

14. Bauer J, Biolo G, Cederholm T et al. Evidence-Based Recommendations for Optimal Dietary Protein Intake in Older People: A Position Paper From the PROT-AGE Study Group. J Am Med Dir Assoc 2013; 14: 542-559.

15. Deutz N, Bauer J, Barazzoni R et al. Protein intake and exercise for optimal muscle function with aging: Recommendations from the ESPEN Expert Group. Clin Nutr 2014; 33: 929-936.

16. de Kerimel J, Tavassoli N, Lafont C et al. How to Manage Frail Older Adults in the Community? Proposal of a Health Promotion Program Experienced in a City of 16,638 Inhabitants in France. J Frailty Aging 2018; 7: 120-126.

17. Jesus P, Desport J, Massoulard A et al. Nutritional assessment and follow-up of residents with and without dementia in nursing homes in the limousin region of France: a health network initiative. J Nutr Health Aging 2012; 16: 504-508.

18. Cesari M, Incalzi R, Zamboni V, Pahor M. Vitamin D hormone: A multitude of 


\section{THE JOURNAL OF NUTRITION, HEALTH \& AGING}

actions potentially influencing the physical function decline in older persons. Geriatr Gerontol Int 2011; 11: 133-142.

19. Basile M, Ciardi L, Crespi I, Saliva E, Bellomo G, Vidali M. Assessing serum concentrations of 25-hydroxy-vitamin D in North-Western Italy. J Frailty Aging 2013; 2: $174-178$.

20. Hamilton B. Vitamin D and Human Skeletal Muscle. Scandinavian Journal of Medicine \& Science in Sports 2009;

21. Hooshmand B, Lokk J, Solomon A et al. Vitamin D in Relation to Cognitive Impairment, Cerebrospinal Fluid Biomarkers, and Brain Volumes. J Gerontol A Biol Sci Med Sci 2014; 69: 1132-1138.

22. Volkert D, Saeglitz C, Gueldenzoph H, Sieber C, Stehle P. Undiagnosed malnutrition and nutrition-related problems in geriatric patients. J Nutr Health Aging 2010; 14: 387-392.

23. Kaiser M, Bauer J, Rämsch C et al. Frequency of malnutrition in older adults: a multinational perspective using the mini nutritional assessment. J Am Geriatr Soc 2010; 58: 1734-1738

24. Ponjoan A, Garre-Olmo J, Blanch J et al. Epidemiology of dementia: prevalence and incidence estimates using validated electronic health records from primary care. Clin Epidemiol 2019; 11: 217-228.

25. Vandewoude MFJ, van Wijngaarden JP, De Maesschalck L, Luiking YC, Van Gossum A. The prevalence and health burden of malnutrition in Belgian older people in the community or residing in nursing homes: results of the NutriAction II study. Aging Clin Exp Res 2019; 31: 175-183.

26. Guigoz Y. Frailty and nutrition: what we have learned from research and clinical practice on the Mini Nutritional Assessment. J Frailty Aging 2012; 1: 52-55.

27. Nieuwenhuizen W, Weenen H, Rigby P, Hetherington M. Older adults and patients in need of nutritional support: review of current treatment options and factors influencing nutritional intake. Clin Nutr (Edinburgh, Scotland) 2010; 29: 160-169.

28. Jadczak AD, Visvanathan R. Anorexia of Aging - An Updated Short Review. J Nutr Health Aging 2019; 23: 306-309.

29. Cox NJ, Morrison L, Ibrahim K, Robinson SM, Sayer AA, Roberts HC. New horizons in appetite and the anorexia of ageing. Age Ageing 2020; 49: 526-534.

30. Probert N, Lööw A, Akner G, Wretenberg P, Andersson ÅG. A Comparison of Patients with Hip Fracture, Ten Years Apart: Morbidity, Malnutrition and Sarcopenia. J Nutr Health Aging 2020; 24: 870-877.

31. Correia M, Hegazi R, Higashiguchi $\mathrm{T}$ et al. Evidence-based recommendations for addressing malnutrition in health care: an updated strategy from the feedM.E. Global Study Group. J Am Med Dir Assoc 2014; 15: 544-550.
32. Thomas D, Ashmen W, Morley J, Evans W. Nutritional management in long-term care: development of a clinical guideline. Council for Nutritional Strategies in LongTerm Care. J Gerontol A Biol Sci Med Sci 2000; 55: M725-34.

33. Nutrition and dementia: A review of available research. London, United Kingdom: Alzheimer's Disease International, 2014.

34. World report on ageing and health. Geneva, Switzerland: World Health Organization, 2015

35. Soysal P, Dokuzlar O, Erken N, Dost Günay FS, Isik AT. The Relationship Between Dementia Subtypes and Nutritional Parameters in Older Adults. J Am Med Dir Assoc 2020;

36. Edington J, Barnes R, Bryan F et al. A prospective randomised controlled trial of nutritional supplementation in malnourished elderly in the community: clinical and health economic outcomes. Clin Nutr 2004; 23: 195-204.

37. Meijers J, Candel M, Schols J, van Bokhorst-de van der Schueren M, Halfens R. Decreasing trends in malnutrition prevalence rates explained by regular audits and feedback. J Nutr 2009; 139: 1381-1386.

38. Integrated care for older people (ICOPE): Guidance for person-centred assessment and pathways in primary care. World Health Organization, 2019.

39. Marzetti E, Sanna T, Calvani R, Bernabei R, Landi F, Cesari M. Brand New Medicine for an Older Society. J Am Med Dir Assoc 2016; 17: 558-559.

40. Rolfson DB, Heckman GA, Bagshaw SM, Robertson D, Hirdes JP, Canadian Frailty Network. Implementing Frailty Measures in the Canadian Healthcare System. J Frailty Aging 2018; 7: 208-216.

41. Sanchez-Rodriguez D, Annweiler C, Gillain S, Vellas B. Implementation of the Integrated Care of Older People (ICOPE) App in Primary Care: New Technologies in Geriatric Care During Quarantine of COVID-19 and Beyond. J Frailty Aging 2020;

42. Cummings J, Passmore P, McGuinness B et al. Souvenaid in the management of mild cognitive impairment: an expert consensus opinion. Alz Res Therapy 2019; 11: 73 .

43. Scheltens P, Twisk JWR, Blesa R et al. Efficacy of Souvenaid in Mild Alzheimer's Disease: Results from a Randomized, Controlled Trial. J Alzheimers Dis 2012; 31: 225-236.

44. Scheltens P, Kamphuis PJGH, Verhey FRJ et al. Efficacy of a medical food in mild Alzheimer's disease: A randomized, controlled trial. Alzheimers Dement 2010; 6: 1-10.e1.

45. Soininen H, Solomon A, Visser PJ et al. 24-month intervention with a specific multinutrient in people with prodromal Alzheimer's disease (LipiDiDiet): a randomised, double-blind, controlled trial. Lancet Neurol 2017; 16: 965-975. 